\title{
Investigating the feasibility of using student reflective journals to understand how clinical legal education can develop the ethical competence of law students
}

\section{Introduction}

This is a feasibility study which aims to assess how student reflective journals can be used to gain an insight into the contribution clinical legal education (CLE) can make to teaching legal ethics to law students. CLE provides real or simulated opportunities for students to provide legal advice and learn through application, practice and reflection in work-integrated contexts ${ }^{1}$ e.g. through student law clinics and CLE modules. Previous empirical studies in this area, ${ }^{23}$ which have focused on if CLE can develop a sense of ethical competence in law students, have argued persuasively that CLE provides an effective vehicle for teaching ethics, and this is now generally supported by academic opinion. ${ }^{45}$ Hardly any attention has however been given to how CLE develops the ethical competence of law students; therefore this study has the potential to be an original contribution to the research in this field.

Self-reflection has been identified as a key feature of CLE in terms of teaching legal ethics, ${ }^{6}$ which enables students to 'learn by doing' and understand the development of professional skills. Nicolson has argued that self-reflection may "enhance understanding and develop the lifelong learning skills of the reflective practitioner." An explicit link has been made between ethical competence and selfreflection by Crowley-Cyr: "a teaching approach that enhances students' reflexive capacity is critical to enabling them to identify and manage ethical challenges." 8 However, the practical use of reflection as a learning tool within law schools generally has not been examined adequately, ${ }^{9}$ which gives added impetus to this study. Self-reflection in the context of teaching legal ethics will be considered further in section two, with specific research questions for this study set out in section three.

Given that this study is concerned with investigating the development of ethical competence in law students, there is a need for some explanation of legal ethical values. In a narrow sense these include professional ethical standards as set

\footnotetext{
1June Chapman, “Why Teach Legal Ethics to Undergraduates?” (2002) 5 Legal Ethics 68, 83.

${ }^{2}$ Richard Moorhead and others, "The Ethical Identity of Law Students" (2016) 23 International Journal of the Legal Profession 235.

${ }^{3}$ Donald Nicolson, "Learning in Justice: Ethical Education in an Extra-Curricular Law Clinic" in Michael Robertson and others (eds), The Ethics Project in Legal Education (Routledge 2011) 171-190.

${ }^{4}$ David Chavkin, "Experience Is the Only Teacher: Bringing Practice to the Teaching of Ethics" in Michael Robertson and others (eds), The Ethics Project in Legal Education (Routledge 2011) 52-78. ${ }^{5}$ William M. Sullivan and others, Educating Lawyers: Preparation for the Profession of Law (2007) 22 <http://archive.carnegiefoundation.org/pdfs/elibrary/elibrary_pdf_632.pdf> accessed 29 October 2018.

'Donald Nicolson, “'Education, Education, Education': Legal, Moral and Clinical” (2008) 42 The Law Teacher 145.

7ibid 164.

${ }^{8}$ Lynda Crowley-Cyr, "Towards ethical literacy by enhancing reflexivity in law students" in Michael Robertson and others (eds), The Ethics Project in Legal Education (Routledge 2011) 142-170, 142. ${ }^{9}$ Mary-Rose Russell, "Reflections on learning: Students' insights on their learning in a legal research skills course in the core curriculum" (2011) 45 The Law Teacher 45, 45.
} 
down in formal codes e.g. the SRA Code of Conduct 2011 for solicitors, which includes key principles such as the duty to uphold the rule of law, act with integrity, act in the best interests of each client and behave in a way that maintains public trust in the legal profession. But ethical competence also covers values in a wider sense that goes beyond the professional ethical codes to include the skills, values and attitudes that guide one's behaviour when providing legal advice, ${ }^{10}$ as well as a sense of public obligation. ${ }^{11}$ In this context values could include, for example, determining whether a lawyer should act for a client irrespective of the morality of their objectives, how far a lawyer should go in pursuing their client's interests, how to reconcile conflicts of interest and whether there should be limits to the lawyer's duty of confidentiality. ${ }^{12}$

Ethically competent lawyers are understood to be able to reflect on these ethical values and develop an ethical framework in which those values apply in order to exercise their own professional judgment. ${ }^{13}$ Understanding the development of ethical competence therefore involves looking for evidence in students of some of the ethical values mentioned above but it also includes exploring whether students are engaging in critical evaluation of self and others. A qualitative case study approach, involving review of student reflective journals and interviews with the same students, appears well suited to this task. This approach also has the potential to explore the issue with more authenticity and detail than previous studies, which have been larger scale and have relied on quantitative methods utilising surveys and questionnaires in capturing the student experience of CLE.

It is expected that the learning from this study, specifically the usefulness of reflective journals as a research method for exploring the contribution of CLE in teaching law students, will be used as the basis for further research in this area. A study on this subject is considered timely in light of the emphasis in the Report of the Legal Education and Training Review ${ }^{14}$ (LETR) on the role ethics should play in legal education. One of the key recommendations of the LETR was to "strengthen requirements for education and training in legal ethics, values and professionalism." 15 The Solicitors' Qualifying Examination (SQE), a new assessment for prospective solicitors that will include testing of ethical competence, is to be introduced by Autumn 2021. The SQE draft assessment objectives relating to ethics, professionalism and judgment broadly refer to ethics in both the narrow and wider

\footnotetext{
${ }^{10}$ Egle Dagilyte and Peter Coe, "Professionalism in Higher Education: Important Not Only for Lawyers" (2014) 48 The Law Teacher 33, 37.

${ }^{11}$ Paula Baron and Lillian Corbin, "Thinking like a Lawyer/Acting Like a Professional: Communities of Practice as a Means of Challenging Orthodox Legal Education” (2012) 46 The Law Teacher 100, 104.

${ }^{12}$ Margie Rowe, Moira Murray and Fiona Westwood, "Professionalism in Pre-Practice Legal Education: An Insight into the Universal Nature of Professionalism and the Development of Professional Identity" (2012) 46 The Law Teacher 120.

${ }^{13}$ Andrew Boon, "Ethics in Legal Education and Training: Four Reports, Three Jurisdictions and a Prospectus" (2002) 5 Legal Ethics 34.

${ }^{14} J u l i a n$ Webb and others, "Setting Standards: The Future of Legal Services Education and Training Regulation in England and Wales" (2013) <www.letr.org.uk/the-report/> accessed 29 October 2018. ${ }^{15}$ Claire Sandford-Couch and Jonathan Bainbridge, "Educating towards Ethical Lawyers: A Progress Report" (2015) 49 The Law Teacher 336, 350.
} 
sense outlined above i.e. including acting both in accordance with legal and regulatory requirements and with honesty and integrity more generally. ${ }^{16}$

A brief review of existing research concerned with self-reflection in a CLE context follows.

\section{Literature review}

Reflection has been defined as "a process to help us learn from our own or others' experiences and to turn that learning into action." 17 It is therefore implicit that reflection involves the capacity in individuals to alter their future behaviour by understanding and learning from their past performances and gaining knowledge through this process. Reflexive ethical capacity, which this study discusses, has been defined by Crowley-Cyr as involving "the readjustment of actions and attitudes in response to new knowledge about the self's actions on others, ultimately to achieve and maintain a higher degree of ethical practice." 18 There are many models of reflection - Crowley-Cyr's for example involves two main steps: firstly, the acquisition of knowledge that results in change in the actor's action and, secondly, the integration of that knowledge. For the purposes of this study it is useful to consider how different models of reflection have been used in previous empirical studies involving law schools, as this informed the methodology and approach to analysis set out in sections four and six below.

A study by Russell examined the effectiveness of the reflection component of a practical skills course based on student writing using a framework formulated by Hatton and Smith. ${ }^{19}$ This model identifies three categories of reflection: descriptive (simply recording the experience), diagnostic (identifying, analysing and judging the experience) and critical (introspective critique of the experience, which is recognised as being applicable to other external contexts). Russell's study involved 215 law students, who were asked to complete an anonymous questionnaire which examined their attitudes to engaging in reflection and to hand in their written reflections for the course. Hatton and Smith's model appears applicable to CLE, where students are required to reflect on their performance, what they are learning and how they might improve. The purpose of Russell's research, however, was to measure the improvement of student learning through reflection rather than to identify how reflection develops ethical competence. A quantitative approach appears less suited to identifying how reflection helps with teaching legal ethics and it seems more appropriate, for the purposes of this study, to explore student experiences using the depth that a more qualitative approach affords.

It is also useful to consider how analysis of student reflection has been conducted in previous empirical studies. A study by Nicolson aimed at contributing to the debate on whether CLE can have a positive impact on ethical development

\footnotetext{
${ }^{16}$ Solicitors Regulation Authority (SRA), "Solicitors Qualifying Examination: Draft Assessment Specification" (2017) <www.sra.org.uk/documents/SRA/news/sqe-draft-assessmentspecification.pdf> accessed 2 September 2018.

${ }^{17}$ Nick Zepke and others, Reflection to Transformation: A Self-help Book for Teachers (New Zealand: Dunmore Press 2003) 17.

${ }^{18}$ Crowley-Cyr (n 8) 154.

${ }^{19}$ Neville Hatton and David Smith, "Reflection in Teacher Education: Towards Definition and Implementation" (1995) 11(1) Teaching and Teacher Education 33.
} 
drew on 23 reflective diaries submitted by students as part of their assessment for a CLE module, analysed using a form of grounded theory. ${ }^{20}$ Nicolson analysed the diaries with the aim of ascertaining what ethical issues were discussed and looking for evidence of moral development generally, however, rather than with a view to understanding the role of reflection in developing this ethical awareness using a specific model of reflection. Another potential limitation of this study was the sole use of the diary approach, given its associated problems of sample bias and inconsistent behaviour as identified by Robson. ${ }^{21}$ Use of a second data collection method may therefore be advisable.

Alternatively, analysis of reflective journals may be more theory-driven than data-driven, where the researcher already has some idea of themes to explore, as in a study by Gibbons. ${ }^{22}$ Gibbons investigated how students built their conceptual legal knowledge by analysing reflective reports using Maton's concept of semantic gravity as a thematic structure for the data analysis. Maton's six codes for semantic gravity include reproductive description, summarising description, interpretation, judgment, generalisation and abstraction. ${ }^{23}$ Gibbons' approach, similarly applied to answering a 'how' question and using a thematic structure for the data analysis based on a specific model of reflection, also appears suited to this study.

While there are many approaches to examining self-reflection, one model is especially relevant to CLE. This model - which requires students to reflect on their performance, what they are learning and how they might improve - is Gibbs's reflective cycle, ${ }^{24}$ which will be used for this study. This model focuses on description ("what happened?"), feelings ("what were you thinking or feeling?"), evaluation ("what was good or bad about the situation?"), analysis ("what sense can you make of the situation?"), conclusion ("what else could you have done?") and action plan ("if the situation arose again, what would you do?"). Although this model provides a loose thematic structure, it is dependent on obtained data for analysis. A potentially rich source of information on both what the students are doing to build knowledge and how they perceive the effectiveness of their approaches, as identified by Nicolson, is through the process of reviewing and analysing their reflective journals. However, there is currently insufficient data available on how students actually gain ethical competence through self-reflection in CLE. This research, which is concerned with conducting a feasibility study of the use of reflective journals within CLE to determine whether and how a full-scale study can be done, is aimed at addressing this gap.

The aims and research question for this study are discussed below.

\section{Research question}

\footnotetext{
${ }^{20}$ Nicolson (n 3).

${ }^{21}$ Colin Robson, Real World Research (2011 London: Wiley) 268.

${ }^{22}$ Jenny Gibbons, "Exploring conceptual legal knowledge building in law students' reflective reports using theoretical constructs from the sociology of education: What, how and why?" (2018) 52 The Law Teacher 38.

${ }^{23}$ Karl Maton, Knowledge and Knowers: Towards a Realist Sociology of Education (London and New York, Routledge, 2014).

${ }^{24}$ Graham Gibbs, Learning by Doing: A Guide to Teaching and Learning Methods (1988 Oxford: Further Education Unit).
} 
The overall aim of this study is to investigate the feasibility of using reflective journals to assess development of ethical competence in law students. Specifically, the research question that I am seeking to answer is:

'Are student reflective journals a feasible method for collecting the data needed to assess how law students use self-reflection to develop their ethical competence?'

There are two practical issues with being able to answer this question: first, obtaining permission to examine these reflective journals; and second, determining the extent to which these reflective journals contain the information needed to assess how law students use self-reflection to develop their ethical competence.

In order to answer the above research question gathering data from students was vital and the next section details how this was done.

\section{Methodology}

\subsection{Research Design and Instruments}

The data collected in this study was qualitative in the form of capturing the lived experiences of undergraduate law students. This study analysed reflective journals prepared by students taking a CLE module. The student reflective journals were available on the relevant virtual learning environment (VLE) at the discretion of the students and the module leader. The self-reflection model used for the analysis was Gibbs's Reflective Cycle. ${ }^{25}$ This model focuses on description, feelings, evaluation, analysis, conclusion and action plan. In relation to self-reflection, what was identified from the journals were the CLE activities and teaching and learning strategies that enabled students to reflect on their performance, what they were learning and how they might improve in order to develop their ethical competence. As identified above, this is an area on which currently there is very little data available.

Thematic analysis was used to analyse the data collected for this study. This approach involves defining the data you are analysing, firstly by coding (i.e. identifying and recording text or other data that in some way exemplify the same theory or idea) and then by grouping the initial codes into a smaller number of themes, which capture something of importance that relates to your research question. ${ }^{26}$ Thematic analysis was used for its flexibility and usefulness in identifying, analysing and reporting patterns within data extracted from the reflective journals. Relevant literature supports the use of thematic analysis for exploratory research, as in the case of this feasibility study, and has known benefits such as providing a rich and detailed description of data. ${ }^{27}$ It took time, thought and close reading to determine codes and themes and they needed to be continually refined by revisiting the data to ensure they were coherent, consistent and distinctive. As pointed out by Coffey and Atkinson, coding is about much more than simply giving categories to data, "it is also about conceptualising the data, raising questions, providing

\footnotetext{
${ }^{25}$ ibid.

${ }^{26}$ Robson (n 21) 474.

${ }^{27}$ Virginia Braun and Victoria Clarke, "Using thematic analysis in psychology" (2006) 3 Qualitative Research in Psychology 77, 83.
} 
provisional answers about the relationships among and within the data, and discovering the data." ${ }^{28}$

Following established guidelines set down by Robson and others, there were several phases in my thematic analysis of the data. I firstly familiarised myself with the data, reading the journals and noting down initial ideas, then generated initial codes. Generating initial codes may be done by interaction with the data, but it may also be done with predetermined codes. ${ }^{29}$ I took the latter approach, which was guided by my reading of the relevant literature and my research question, in coming up with initial codes based on Gibbs's reflective cycle: description, feelings, evaluation, analysis, conclusion and action plan. I then collated the codes into three potential themes, which were again guided by the literature in that they accorded closely with Hatton and Smith's categories of reflection: descriptive, diagnostic and critical. In taking this approach I was aware that it could be argued that such prespecification might bias me towards some aspects of the data, however, in my view the counter argument that prior engagement with the literature might enhance the analysis by sensitizing me to features of the data that could otherwise be missed was equally compelling. The final stages of the analysis involved exploring, describing, summarising and interpreting patterns within the data.

This is an institutional case study (i.e. where there is a detailed focus on a single or small number of cases in the researcher's "home" setting, taking its context into account) and its findings are not intended to be statistically significant. However, statistical generalizability is not the aim of this study; rather it is to provide insight into and understanding of a method of research into a method of teaching. As pointed out by Delamont and Hamilton: "through the detailed study of one particular context it is still possible to clarify relationships, pinpoint critical processes and identify common phenomena" 30 - it is considered that these kinds of generalisations are equally useful. In relation to the value of this research it is also relevant that case study research offers a distinct type of knowledge: exemplary knowledge, which draws its validity from phronesis (the fact that it is corrigible and interpretable in the context of experience) rather than from theory or objective verification or refutation. ${ }^{31}$ Whilst it does not necessarily involve selection of a representative sample, there is potentially still a firm basis as to the validity of the findings of a qualitative study such as this one as long as the relevant quality criteria for qualitative research are borne in mind. These include credibility, dependability, transferability and confirmability. ${ }^{32}$ In this context, threats to validity in qualitative research such as bias, inaccuracy and incompleteness of data can be countered by methodological rigour, sensitivity to ethical issues, thorough data collection and keeping an audit trail.

\footnotetext{
${ }^{28}$ Amanda Coffey and Paul Atkinson, "Concepts and Coding" in Making Sense of Qualitative Data: Complementary Research Strategies (And Social Thought) (1996 London: Sage) 26-53, 31.

${ }^{29}$ Robson (n 21) 479.

${ }^{30}$ Sara Delamont, and David Hamilton, "Revisiting Classroom Research: a continuing cautionary tale", Readings on Interaction in the Classroom (1984) 3-24, 19.

${ }^{31}$ Gary Thomas, "The Case: Generalisation, theory and phronesis in case study" (2011) 37 Oxford Review of Education 21.

${ }^{32}$ Martyn Denscombe, The Good Research Guide for Small-Scale Social Research Projects (2017 London: Open University Press) 299.
} 
It is also important to highlight the distinctive features of a feasibility study. As stated by Orsmond and Cohn, "feasibility studies are designed to answer the overarching question: Can it work?"33 Denscombe offers further guidance on what answering the question of 'Can it work?' means in a feasibility study. Important questions for a researcher in this context include whether there is sufficient time for the design, collection of data and analysis of results; whether sufficient resources are available to cover the costs of the research (e.g. transport and printing); and whether it is possible and practical to gain access to necessary data (e.g. people and documents). ${ }^{34}$ Some preliminary evaluation of the data collected will also be necessary in order to establish whether the methods of data collection and analysis show promise. All of this makes a sound argument for a feasibility study to be conducted prior to more in-depth research; indeed, a significant amount of time and resources may be wasted if feasibility has not been carefully examined.

The institutional context for this study was the CLE module at the University of East London (UEL) and the participants were undergraduate law students taking this CLE module at UEL. This is an option module for final year students, delivered through small group encounters where students are exposed to real and simulated clinical experiences. The CLE module aims to enable students to benefit from the various forms of clinical legal education and the role of reflection during the module. The module does not follow the model of having separate lectures and seminars but is instead delivered through 24 weekly 3 hour long workshops (small group encounters where students explore the study of law through practical experiences such as advising, drafting, mooting, debating, negotiation, mediation and so on). These include simulations (e.g. of client interviews) but students taking the module also advise real clients in the university's legal advice centre (law clinic). The law clinic is a learning facility at UEL where law students offer free written legal advice to members of the public who are unable to pay or obtain public funding for such advice. Students maintain an e-portfolio on the VLE for the CLE module, where they keep their reflective journals and upload any supporting materials. Module content includes legal professional conduct and ethics and learning outcomes cover analysis of the significance of reflection and feedback, with workshop task instructions requiring students to apply professional ethics in a practical setting and assessment criteria expressly asking for evaluation of the importance of professional ethics. Evaluation of ethical competence is therefore very much within the scope of this CLE module. This makes a preliminary feasibility study in this context particularly useful prior to a larger scale study with the purpose of assessing the development of ethical competence in law students.

Sampling of participants was unnecessary as only ten students were enrolled on this module. To avoid further limiting the already small population of potential participants this body of students was therefore approached in its entirety. It was also necessary to get initial consent from the lecturer responsible for the module before any students were approached. Ultimately, both the module leader and the

\footnotetext{
${ }^{33}$ Gael Orsmond and Ellen Cohn, "The distinctive features of a feasibility study: Objectives and guiding questions" (2015) 35 OTJR Occupation, Participation and Health 169, 169.

${ }^{34}$ Denscombe (n 32).
} 
six students included in this research gave their consent to the use of their reflective journals for this study. It is important to emphasise that permission to review student reflective journals for the purposes of this study was only granted after they were written, not before, otherwise this might have affected the manner in which students recorded their experiences.

\section{Ethical Issues}

Before commencing this institutional case study, steps were taken to ensure that it followed proper ethical guidelines, bearing in mind that perhaps "the most dangerous and difficult place to attempt qualitative research is in a familiar institutional setting." ${ }^{35}$ Full ethics clearance was obtained from the university's research ethics committee before commencing any data collection. During the study all participants were notified that their involvement was completely voluntary and could be withdrawn at any time. Although there are limitations to the extent to which consent can ever be fully informed, every effort was made to safeguard against these issues e.g. through the use of an information sheet and informed consent form. I was also aware of the dual nature of my role in this study as both a lecturer at UEL and a researcher. The reflective journals used for the study are formally assessed as part of the CLE module by the module leader and are therefore not intended to be private. I am not, however, involved in assessing these journals this study was therefore entirely independent of any assessment process and this was made clear to the participants.

Availability of the sample depended on both the CLE module leader and students taking the module granting me access to their reflective diaries kept on the VLE. I was aware of the potentially sensitive nature of the material in the journals and there was a possibility that both the module leader and students may not have consented. This risk was mitigated by making every effort to ensure that the research was carried out in an open and honest manner; that participation was voluntary and based on informed consent; that participants were not coerced to participate, had the right to withdraw at any time, were not in any way misled about their participation, did not suffer any personal, physical or psychological harm as a result of this study and all data collected from them were stored and processed securely in encrypted files.

To reduce any reluctance to consent from the module leader and students, I emphasised how taking part in this study might help both lecturers and students to get more out of CLE in future by reflecting upon their experiences, as well as possibly providing experience of research and questioning techniques for students that might be of benefit to them in future. I also confirmed that, while a summary of key findings would be provided to those involved, participants would be anonymised. I was also aware that having the module leader as a gatekeeper may put the students in a vulnerable position (e.g. not feeling free to withhold their consent) but other steps were taken to protect participant autonomy e.g. through informed consent and the right to withdraw such consent.

\footnotetext{
${ }^{35}$ Susan Malone, "Ethics at home: Informed consent in your own backyard" (2003) 16 International Journal of Qualitative Studies in Education 797, 812.
} 
Having discussed the study's analysis approach and ethical process, I now present below the findings from this research. Within a qualitative approach, analysis is often integrated within the findings. Consequently, the below section also explains my process for obtaining the sample of journals and for deriving the analytical themes for my findings.

\section{Findings}

\subsection{Obtaining the Sample}

The module leader and six out of the ten students enrolled on the CLE module (referred to as A, B, C, D, E and F) provided the requisite consent. The sample of reflective journals varied somewhat in terms of length and presentation, with students writing anything from 2,100 to 6,600 words and some students covering all 24 workshops while others only wrote about half that number. The style and content of the journals also varied, with some students writing in a more formal 'essay' style (e.g. making more use of quotes and references), while others wrote in a more informal 'journal' style (e.g. writing mostly in the first person with far fewer quotes and references). Despite this variability in content, all the individual journal entries for each student were ordered by reference to each separate workshop and in all cases the entries were longer and more detailed for the later workshops. For the sake of authenticity, all direct quotes from the data that follow are presented without correction of spelling, punctuation or grammar.

\subsection{Developing the thematic codes}

After familiarising myself with the data through in-depth reading of the journals, I made notes of what stood out in the data - in particular aspects that might form the basis of repeated patterns such as specific events, activities and behaviours i.e. what the students did and said. This part of the analysis involved organising the data into meaningful groups i.e. codes, which refer to "the most basic segment, or element, of the raw data or information that can be assessed in a meaningful way regarding the phenomenon." ${ }^{36}$ As I was coding manually, I wrote notes on the texts I was analysing and used coloured highlighter pens to indicate potential codes and themes. During this process I kept in mind that I needed to code for as many potential themes as possible and that extracts of data needed to be coded inclusively to avoid losing the context in terms of the surrounding data. ${ }^{37}$ Six initial codes were generated during this phase of the thematic analysis: description, feelings, evaluation, analysis, conclusion and action plan.

Although the codes were to some extent pre-specified, drawing on my knowledge of previous research, they also tallied closely with the data, suggesting some familiarity with Gibbs's model of reflection on the part of the students, albeit a superficial one in some cases. By way of illustration, all entries by students started with a description of what happened (e.g. "On the $17^{\text {th }}$ April 2018, we took part in a

\footnotetext{
${ }^{36}$ Richard Boyatzis, “Developing Themes and Codes" in Transforming Qualitative Information: Thematic Analysis and Code Development (1998) 63.

${ }^{37}$ Alan Bryman, Social Research Methods (2016: OUP) 585.
} 
mediation role-play exercise") and their feelings about this ("I felt I was able to enact my role confidently"), then went on to state what was good or bad about the situation ("I think I could have improved by giving more complex answers" i.e. evaluation) and what sense they could make out of this ("This could have made my presentation more interesting" i.e. analysis), and finished with a conclusion (e.g. "It gave me an insight of what could happen in a real-life situation") and an action plan of what they would do in future ("I believe that these sessions helped me build my confidence for what I want to do in the future"). The reflective accounts were always in this order, divided into three distinct paragraphs or sections in the process. The difference between each student tended to be the length of each section, with some students writing more on their description and feelings, some including more evaluation and analysis and others talking more about their conclusions and action plans. Legal ethics was rarely considered openly by any of the students, except in their entries for the specific Professional Conduct and Ethics workshop on the course (e.g. "The solicitor's handbook from the SRA is divided into 6 chapters. The chapter which forced me to think deeper was on confidentiality"). Otherwise, professional and ethical issues were considered indirectly, usually under the conclusion section or their action plans (e.g. "From this session, I have learnt the importance of drafting legal writing so I come across professional and well informed").

\subsection{Themes}

In the next phase of the analysis, I started to develop themes - this is where the interpretative analysis of the data occurred. I already had some themes in mind when doing the initial coding, again arising from reviewing the literature. Searching for themes involved sorting the different codes and considering how they could be combined to form an overarching theme by looking for repetitions, transitions, similarities, differences and so on. After coming up with the initial list of themes, these themes needed to be reviewed in order to ensure that data within themes cohered meaningfully, with clear and identifiable distinctions between them. Finally, the themes were defined and named, with examples found to illustrate each theme.

I put together description and feelings to form the theme of descriptive reflection. This involved simply detailing the experience (e.g. a brief description of a mooting and debating workshop and the student's feelings about it at the start of the journal entry). Evaluation and analysis were combined to form the theme of diagnostic reflection, which was characterised by the students thinking more carefully about their experience and evaluating or analysing it by reference to a specific issue or learning outcome (e.g. the student's assessment of their own performance during the mooting and feedback workshop and identification of the importance of the session). Finally, the conclusion and action plan sections together formed the theme of critical reflection. In this theme students weighed up their experiences and considered them more widely, beyond the module and on a more personal level or in the context of their future goals and aspirations (e.g. a summation at the end of the journal entry of what the student thought came out of the mooting and feedback workshop and how this could be applied in their future work in the legal profession). Ethics, if considered at all (as stated above, ethical considerations rarely came up in the journals), tended to arise in the context of the 
theme of diagnostic reflection, as an issue around assessment or as a curriculum outcome.

The above described the process of deriving the thematic codes and analysis process. These analysis stages are followed by integration and interpretation i.e. 'generating meaning' from the data, codes and themes, ${ }^{38}$ which is discussed in the final section below. The interpretation stage included looking for patterns and trends, noting the frequency of occurrence of recurrent events, making contrasts and comparisons and attempting to make conceptual coherence.

\subsection{Interpreting the data within the analytical themes}

An interesting pattern that emerged from the themes I identified was a link between critical reflection and the length of the reflective journal. There was a marked difference for example in the word count between the three longest journals belonging to $B(6,600$ words approximately), $E(5,100)$ and $F(4,700)$ - and the three shortest - belonging to $A(2,500), C(2,100)$ and $D(2,300)$. All of the shorter journals focused more on descriptive reflection, with comparatively little on critical reflection, while the reverse was the case for the three longer journals.

$I$ also identified interesting differences in the quality of critical reflection between the journals. For example, the three shorter journals varied in their conclusions and action plans being characterised by the re-use of words and phrases such as "overall" and "in the future". The longer journals also tended to be more nuanced in the final section of each entry, with critical reflection typically identifying a particular skill being learned from an individual workshop (e.g. research, drafting, advocacy etc.) and a context in which to apply it in future (e.g. meetings with clients, preparing for trials, letter writing etc.). The longer journals also tended to be written in a more informal style, including fewer quotes and references than the others, despite the fact that those journals were shorter overall.

I identified that student reflection itself was highly subjective and varied. Some students focused more on reflecting on academic opinion, policy documents and case law (e.g. D quoted extensively from the websites of the National Autistic Society, the University of Oxford and the Qatar Debate Centre in her reflection). Others placed emphasis on a more personal discussion of feelings, motivations and character traits (e.g. E also quoted from a range of sources but contextualised this by, for example, talking about the challenges he encountered in questioning mock clients in a practical mediation exercise). However, the reflective accounts were all marked by a striking level of honesty, bearing in mind that these were not private diaries, with students openly discussing their hopes, fears and perceived strengths and weaknesses in the context of legal education and practice (e.g. F said that "Acting as the mediator was challenging as I found myself out of my usual comfort zone"). Students also frequently spoke about how they anticipated making practical use of their experiences on the module (e.g. B's reflection on a legal advice workshop was that "This therefore taught me that research is key before going in to any meetings with clients").

\footnotetext{
${ }^{38}$ Matthew Miles and Michael Huberman, Qualitative data analysis: an expanded sourcebook (1994 London: Sage) 245-6.
} 
In summary, the analytical process described above produced three themes: descriptive, diagnostic and critical reflection. These themes were to some extent pre-specified by a reading of the literature (specifically Hatton and Smith's model of reflection) but they also accorded closely with the data. Above I note a number of interesting patterns to come out of the data: a link between critical reflection and the length of the reflective journal, differences in the quality of critical reflection and student reflection was highly subjective and varied. I now go on to draw some conclusions below about this section, including the process of analysis and interpretations of my data in order to address the research question posed in section three above, and to consider how to develop this research.

\section{Conclusions}

The aim of this study was to assess how student reflective journals can be used to gain an insight into the contribution CLE can make to teaching legal ethics to law students. Specifically, I sought to answer the following research question: 'Are student reflective journals a feasible method for collecting the data needed to assess how law students use self-reflection to develop their ethical competence?' As discussed in section three, the two practical issues with being able to answer this question included: first, obtaining permission to examine these reflective journals; and second, determining the extent to which these reflective journals contain the information needed to assess how law students use self-reflection to develop their ethical competence. In this sense I am satisfied that the main research question was answered affirmatively: gaining access to the necessary data was both possible and practical, and the information contained in the reflective journals showed considerable promise for the purpose of assessing how law students use selfreflection to develop their ethical competence. I am also confident that there was sufficient attention to appropriate ethical considerations, suitability of methodology, thoroughness of data collection, depth and breadth of analysis and clarity and presentation of reporting to justify the validity of the findings of this study by reference to the quality criteria discussed in section four in terms of credibility, dependability, transferability and confirmability.

The major qualification to this conclusion is the imperative for triangulation, which necessitates additional methods of data collection and analysis for the benefit of any claims that can be made as to the value of such research. As identified in Nicolson's study, referred to in section two, the limitation of relying on these reflective accounts as evidence of the impact of CLE on students' ethical development is that they largely illustrate simply what students say they did and felt, rather than how they actually behaved. On reflection, it would have been useful to have also used a second data collection method, perhaps using classroom observation and/or interviews with the same students, which would have helped me to better understand how closely the journals represented the students' actual behaviour. Another limitation of this study is the possibility of subconscious bias in the interpretation of the data on my part, as a researcher with an interest in the role of CLE in developing ethical competence through reflection. A larger sample might also have been beneficial to provide a greater range of data on reflection. However, despite these qualifications, to the extent that the findings of this study represent a 
plausible reading of genuine views, there is a strong case to be made for using student reflective journals to understand how CLE can develop the ethical competence of law students.

The objective of this study was limited to an investigation of the feasibility of a particular methodology i.e. using reflective journals to assess development of ethical competence in law students. However, from the outset, as explained above in sections one and four, the purpose of conducting a study of feasibility was to gain an insight into the contribution CLE can make to teaching legal ethics prior to more in-depth research on a larger scale. Having established from preliminary evaluation of the data collected that the methods of data collection and analysis show promise, it is useful to consider how to develop this research. A next step therefore could be to repeat this study with future cohorts of law students taking the CLE module at UEL. In light of the limitations identified above of restricting the study to the review of reflective journals, future research would need to first involve analysis of student reflective journals to assess how their ethical competence is being developed, followed by interviews that would then take place with the same students in an effort to reveal further information not covered in the journals. In these interviews questions could be directed at identifying what CLE experiences enable students to reflect on their performance, what they are learning and how they might improve in order to develop their ethical competence. Data from the review of self-reflective journals could then be triangulated with answers to interviews to give a more complete picture, given the limitations of the sole use of the diary approach identified above. The validity of findings can best be checked by using contrasting sources of information to provide a more complete picture, although it also opens up the potential for contradictions between the different sources. ${ }^{39}$ In view of the inevitably small size of the sample (given that it is unlikely that there will be any great expansion in the use of CLE at UEL in the foreseeable future), consideration could also be given to collaborating with colleagues at other institutions. Discussion with colleagues of this methodology and its transferability could potentially provide the basis for a more significant piece of research with greater validity in the future.

\footnotetext{
${ }^{39}$ Bryman (n 37) 386.
} 